\title{
Uma História e Perspectivas na Psicologia do Desenvolvimento: Com a Palavra Thereza Mettel ${ }^{1}$
}

\author{
Entrevista com Thereza Mettel \\ A History and Perspectives in Developmental Psychology: \\ With the Word Thereza Mettel
}

\author{
Interview with Thereza Mettel
}

\begin{abstract}
A Profa. Dra. Thereza Pontual de Lemos Mettel, membro fundador de nosso Laboratório, prestou um admirável conjunto de contribuições efetivas à Psicologia brasileira. Suas contribuições fundamentais à Psicologia não se restringiram, em absoluto, às areas de Psicologia do Desenvolvimento Humano e Psicologia Escolar, visto que Thereza Mettel em muito colaborou com a área da saúde e com o desenvolvimento da ciência e da profissão no Brasil. Isto se deu em quatro instâncias: 1) primeiramente, colaborou com substancial e efetiva participação na introdução e consolidação, no país, da pesquisa científica nas áreas de Psicologia Clínica, do desenvolvimento humano e saúde; 2) teve papel essencial na formação de alto nível de docentes, pesquisadores e psicólogos; 3) pela sua incansável atuação, contribuiu diretamente para a estruturação e o funcionamento dos Conselhos de Psicologia no Brasil, colaborando de forma fundamental na organização e consolidação da profissão de psicólogo no país; e finalmente, 4) colaborou com trabalho intensivo na organização e desenvolvimento da pós-graduação e pesquisa na área da Psicologia no país, atuando como consultora em orgãos de fomento e, em especial, tendo papel de grande destaque na fundação da ANPEPP (Associação Nacional de Pesquisa e Pós-Graduação em Psicologia).
\end{abstract}

Foi considerando sua valiosa contribuição à Psicologia que decidimos entrevistar a Prof ${ }^{a}$. Thereza Mettel, para que todos pudessem partilhar um pouco de suas idéias e concepções sobre a Psicologia enquanto ciência e profissão, idéias estas que resultam de toda uma vida dedicada ao trabalho profissional e, especialmente, à formação de psicólogos e pesquisadores no âmbito da Psicologia.

Visitamos a Prof ${ }^{a}$. Thereza Mettel, aposentada pela Universidade de Brasília, em sua residência. Sua entrevista encontra-se transcrita após apresentarmos algumas informações e considerações que julgamos importantes para situar o leitor quanto à experiência e a qualidade do trabalho desenvolvido pela Prof ${ }^{\mathrm{a}}$. Thereza ao longo de sua trajetória profissional realizada no Brasil e no exterior.

1 Entrevista concedida ao Laboratório de Microgênese nas Interações Sociais, PED/IP/UnB. A Revista agradece às Profas. Angela Branco, Diva Maciel e Micheline Silva pelo texto aqui apresentado.
Diante do papel pioneiro e fundamental à Psicologia no país desempenhado por Thereza e por seus colegas, alguns deles também agraciados com o título de Professor Emérito da Universidade de Brasília no ano de 2006 (Drs. João Cláudio Todorov, Luís Pasquali, Júlia Bucher, Álvaro Tamayo, Jorge Ponciano Ribeiro e Richard Bucher), foi que decidimos registrar suas idéias por meio de uma entrevista realizada em sua residência no dia 5 de setembro de 2006, que contou com a participação das professoras Angela Branco e Diva Maciel.

\section{Entrevista}

Diva - E então, Thereza, como foi que surgiu o seu interesse pela Psicologia do Desenvolvimento?

Thereza - Eu comecei a minha vida profissional na Psicologia na área clínica trabalhando com crianças e adolescentes. Quer dizer, a minha vida praticamente inteira foi trabalhando com crianças e adolescntes. E aí, que havia no Brasil, uma Psicologia ligada à área médica, à Psiquiatria. E quando eu fui para os Estados Unidos, eu continuei trabalhando com adolescentes e com crianças, mesmo quando não era na área clínica. E, ao final de algum tempo, eu fiquei interessada no processo de desenvolvimento, dessas problemáticas, do porquê de uma criança aparecer com problemas que precisavam de um psicólogo intervir. Eu achei que trabalhar só no final, quer dizer, quando já havia a problemática instalada, era pouco. Eu comecei a me interessar pelo processo de desenvolvimento humano, como é que ele se dá nas relações da criança com a família, como é que a criança se desenvolvia normalmente, e como se desenvolviam os processos patológicos. Foi assim que, no final, quando começou esse processo, depois que eu voltei dos Estados Unidos, da segunda vez, lá em Ribeirão Preto, que eu comecei a ler e a me interessar pela área da Psicologia do Desenvolvimento. Aí, quando eu fui para a Inglaterra, para trabalhar com o Blurton Jones e com o Connolly, eu já estava engatilhada na área da Psicologia do Desenvolvimento e interessada nos métodos de observação, inclusive no ambiente natural. (...) eu conheci a Clotilde [Rossetti-Ferreira], que tinha trabalhado com o Blurton Jones quando eu estava em Ribeirão Preto, mas fui para a Inglaterra depois que estava já aqui em Brasilia. E daí em diante deslanchou todo o meu interesse pela área da Psicologia do Desenvolvimento, embora eu tenha continuado a trabalhar profissionalmente na clínica. Então foi assim que se deu. 
Diva - Você falou da influência do Blurton Jones, e do trabalho, do estudo que você foi fazer na Inglaterra... Como, na sua época, as teorias e as pesquisas eram realizadas?

Thereza - Na área da Psicologia do Desenvolvimento?

\section{Diva - Sim, da saúde, na área clínica...}

Thereza - Por exemplo, eu, quando fiz a minha tese de doutorado, eu já trabalhei numa visão sistêmica, e também numa visão rogeriana, e essas foram as espinhas dorsais da minha tese. Quer dizer, eu já tinha, naquela época, uma visão sistêmica. Tanto que quando eu fui fazer a minha tese de doutorado, eu usei entrevistas, mas o foco na interação era predominante, a interação cliente-entrevistador. Essa era uma hipótese do Rogers, e a parte de análise, teve uma parte quantitativa e uma parte qualitativa. Quer dizer, já era uma inovação, a gente já fazia uma análise, através de gravações, inclusive valorizando o silêncio, e então fazia uma interpretação. Isto era o prenúncio da análise qualitativa que hoje se faz, quer dizer, é o tipo de análise que se encontra hoje, e que vai além da parte quantitativa que nós éramos obrigados a fazer. Nessa época, na época que eu defendi a tese, há muitos anos atrás, em 1963, era praticamente parte do trabalho de pesquisa na Psicologia o uso de métodos quantitativos, inclusive lá na Universidade de Winsconsin. Essa era a metodologia praticamente obrigatória para todas as teses realizadas. Então, isso é interessante, havia uma exigência de um determinado tipo de metodologia que tinha que ser usada nas pesquisas em Psicologia. Mesmo na pesquisa clínica, ela tinha que ter uma parte numérica e quantitativa que se analisava no computador. Eu participei de uma pesquisa, como auxiliar de pesquisa do Rogers onde a gente analisava o relacionamento psicoclínico com o entrevistador, o uso do gravador foi introduzido, era o gravador de rolão, mas já tinha o modelo portátil, de fita grande. Nós gravávamos, e alguém anotava coisas importantes, por exemplo, o catatônico, que ficava parado numa posição só, e depois nós analisávamos. É por isso que o meu interesse, mais tarde, quando eu entrei na área da Psicologia do Desenvolvimento, foi de estudar, usar métodos etológicos. Eu achei que era um grande progresso a gente sair do laboratório, porque com o Rogers nós estudávamos o paciente dentro do hospital, já não mais em uma sala de entrevista. Isto significa que havia uma relação entre os objetivos da pesquisa, a metodologia e a teoria que estava por trás. Evidente que hoje isso é muito mais específico, e é intencional. Mas na época, há muitos anos atrás, a Psicologia, para ser científica, ela tinha realmente que seguir a metodologia aceita na época pelas áreas da ciência, daí a necessidade de usar métodos estatísticos. A estatística era muito mais presente nos projetos de pesquisa do que hoje. É evidente que hoje tem áreas que são praticamente qualitativas.

Diva - Em termos teóricos, como você descreveria sua trajetória dentro da Psicologia?

Thereza - Eu comecei a minha vida profissional no período não havia curso de Psicologia. Na época, realizavamos cursos específicos, era o treinamento em Psicologia que todo mundo fazia. Depois quando eu fui para os Estados Unidos continuei meu treinamento com a orientação rogeriana, que já tinha aqui no Brasil. Quando eu tive a bolsa, escolhi Winsconsin justamente porque Carl Rogers se encontrava lá. Consegui uma bolsa e fiquei para realizar o curso de Mestrado e Doutorado.

Diva - Que outros teóricos além de Rogers tiveram influência? Um papel importante na sua formação?

Thereza - Acontece que esse respeito pela pessoa humana, pelo processo de interação e relacionamento, continua até hoje, através das minhas mudanças (...) Quando fui trabalhar com crianças com problemas graves, com crianças autistas, com crianças com retardo, vi que era preciso ter uma metodologia que a rogeriana não dava conta. Aquele tipo de entrevista, de interação, precisava uma interação mais ativa, com uma programação melhor. Então eu encontrei essas respostas na modificação do comportamento, na terapia comportamental. Aí tive contato com a equipe que trabalhava com essa orientação, fazendo um curso de especialização com aquele pessoal. Depois fiz um curso com o Lovaas, que trabalhava com crianças autistas, ele foi a Winsconsin, deu um curso, e eu fiz esse curso com ele. Depois fui trabalhar no Children's Treatment Center, enquanto estava lá em Winscosin, isso foi da segunda vez que eu voltei. E aí desenvolvi uma capacidade de entender o comportamento visto com controles por contingências, e entendendo também o ambiente, a história da pessoa, do organismo, e tentando fazer, então, de uma maneira ativa, a modificação do comportamento. Nós trabalhávamos com crianças autistas que se auto-mutilavam, que não faziam contato visual, e a gente trabalhava também com fobias. Esse tipo de enfoque realmente é muito útil ainda hoje no tratamento desse tipo de problema. Eu trouxe essa possibilidade para o Brasil, e foi na Universidade de São Paulo, quando fui contratada pela Faculdade de Medicina, que dei disciplinas sobre Análise Comportamental Aplicada. Alguns vinham e faziam cursinho de verão, faziam atendimento de casos, crianças que arrancavam os cabelos, crianças agressivas. Mas desde essa época, a minha formação rogeriana influenciou a minha prática. Então, eu acho que isso é interessante porque as teorias existem para serem aplicadas, e serem aplicadas com a criatividade do pesquisador. Uma das contribuições que eu recebi tanto de Rogers quanto da Psicologia Comportamental Aplicada é que a gente tem que ter a pesquisa ligada à prática clínica. Isso eu sempre fiz na minha vida. Nós colhíamos dados, fazíamos uma pesquisa para cada caso, fazíamos um planejamento, uma análise do caso, e também uma avaliação. Nós fizemos salas específicas, com gravador, com espelho unidirecional, e enquanto o meu aluno atendia a criança dentro da sala a gente observava. No início, tínhamos até fones de ouvidos para darmos orientação, e o atendimento era gravado. Foi a união da pesquisa com o atendimento clínico.

Quando eu voltei para o Brasil [após estágio pós-doutoral na Inglaterra], enquanto trabalhava na área clínica, eu também desenvolvia a observação de crianças no ambiente natural, principalmente a interação entre as crianças e entre as crianças e as mães. No meu trabalho clínico eu introduzi a família, comecei a trabalhar no Brasil como lá nos Estados Unidos. Eu trabalhava com a família, o que era uma coisa relativamente nova. Nos Estados Unidos, a criança nunca era atendida sozinha. Mas quem atendia a mãe era a assistente social e o psicólogo atendia a criança. Então, meu trabalho com a família vem desde o início da minha vida profissio- 
nal. É preciso realizar um trabalho conjunto, o psicólogo, a família, a criança, e até mesmo o atendimento conjunto da mãe e da criança na sala de atendimento.

Diva - Além do trabalho com a família, que outros aspectos você considera importantes, que você chamava atenção....

Thereza - Bom, na minha tese eu já fiz uma abertura para a concepção sistêmica, que Bronfebrenner depois propôs, e essa visão tem seguido a minha vida profissional, essa criação de várias vertentes. Não adianta você trabalhar só com a criança, porque ela faz parte de um sistema, de um sistema familiar, escolar. Nós começamos nosso trabalho com a criança com uma visão global, trabalhando em conjunto a família, a escola, e a criança. O atendimento à criança era apenas parte do tratamento. E os alunos aprendiam, assim, a importância da visão sistêmica. $\mathrm{O}$ atendimento à família, a terapia familiar, esta é mais recente. Em Ribeirão, eu cheguei a atender casais que precisavam de atendimento, via a criança e depois via o casal, então era um atendimento bastante complexo. (...) o Bronfenbrenner, as teorias do sistema, a etologia, inspirararam o meu trabalho. De Rogers, permaneceu a importância dos relacionamentos. Isso é importante porque muitas das pessoas que trabalhavam na Terapia Comportamental não consideravam isso. Eu fiz uma palestra uma vez numa das reuniões em Ribeirão sobre a importância da interação terapeuta-cliente, uma coisa importante para os nossos alunos da Faculdade de Medicina. É fundamental você descer ao nível da criança, e ter com ela essa empatia, procurar nivelar. A empatia era um conceito rogeriano e eu fui passando para os meus alunos, para que eles desenvolvessem essa capacidade de se relacionar de uma maneira positiva com a criança com quem estava trabalhando. (...) [Por exemplo], trabalhar o relacionamento é uma coisa básica no tratamento de crianças autistas, e não somente usar a técnica de modifiação de comportamento. É aquela técnica vestida com os aspectos do relacionamento, que permite ver o lado do outro e ser capaz de procurar, no seu repertório, aqueles aspectos que sintonizam, a sintonia do relacionamento, este é o nosso trabalho. (...)

$\mathrm{Na}$ época em que trabalhei em uma clínica multidisciplinar, atendíamos crianças com problemas de ranger de dentes, de enurese, de arrancar cabelo, de agressividade excessiva. Fazíamos orientação dos pais, e já partíamos daí para a prevenção. (...) Meu período em Ribeirão, dentro da Faculdade de Medicina, me abriu, fui obrigada a entrar na área da saúde, e me aproximei da pediatria. Aí começou o meu interesse pela Psicologia na área da Saúde... (...) Eu comecei entrando em uma equipe multidisciplinar da Faculdade de Medicina, como o psicólogo que faz parte da equipe, tomando decisões, trabalhando com profissionais de saúde. (...) dentro da Pediatria, atuei como uma pessoa dentro da equipe que dava as suas contribuções para o entendimento do quadro clínico. Ali, também, no atendimento de criança hospitalizada, esse foi o início da minha interação com a área de saúde, com a qual continuei quando vim aqui pra Brasilia.

Diva - Esse seu trabalho que você começou a construir na Psicologia da saúde teve sempre uma temática, uma perspectiva de desenvolvimento...
Thereza - Teve sim porque, por exemplo, quando eu vim pra Brasília estavam começando a introduzir isso, em termos médicos, na Pediatria, de introduzir a mãe na enfermaria. Mas faltava um trabalho com essas mães. Então se faziam trabalhos de pesquisa comparando as crianças internadas com a mãe e as crianças internadas sem a mãe, e a questão da hospitalismo. (...) Mas o nosso foco ainda era a criança. Aí a Célia [Célia Maria Zannon], a tese dela de doutorado foi baseada nisso, um interesse também pela área da Psicologia do Desenvolvimento, e já não apenas uma visão clínica. (...) Quer dizer, a Psicologia Clínica precisa da Psicologia do Desenvolvimento para entender os processos na área da saúde. (...). A questão do psicólogo dentro do hospital é diferente do terapeuta, ele tem as suas habilidades clínicas, mas também precisa ter um conhecimento da organização e do trabalho em equipe... Quando eu vim pra Brasilia, eu trabalhei em um centro de saúde familiar, acompanhando um projeto, que a universidade criou, de recuperação de crianças desnutridas, nós participamos ativamente desse projeto. E o nosso trabalho era estudar, conhecer, analisar, e depois conversar com os médicos para estabelecer, melhorar a comunicação deles com os pacientes, acompanhando a criança também em casa.

\section{Diva - E a questão da teoria, como você vê?}

Thereza - A teoria ela não é estática, ela foi feita para interpretar a realidade. Elas têm uma relação mútua, e precisam ser testadas... É evidente que a Psicologia tem uma variedade enorme de enfoques, e esses enfoques não são estanques. Quando se tem uma posição não-radical, elas têm pontos de interseção que podem ser explorados para serem testados na prática. O que não pode é a pessoa ser sincrética, voce tem que ter uma direção, mas essa linha tem que evoluir diante da complexidade dos processos, e também de acordo com as necessidades de interpretação da realidade. Então, eu vejo isso também, que seria importante que fosse feita uma análise de algumas teorias em Psicologia e que se buscassem os pontos de contato que existem entre elas. A Psicologia tem a sua pluralidade, como a Biologia também tem, a própria física também, mas é importante ter este pontos de contato que permitam um aperfeiçoamento, e que sejam elaborados pragmaticamente alguns modos de se trabalhar, de se interpretar a realidade. Porque um dos problemas que a Psicologia tem é você ficar fanático, assumir uma ou outra teoria como se aquela fosse a verdade. Isso não existe em ciência, não existe "a" verdade, mas sempre a procura da verdade. Não se pode ser mais paroquial com relação a isto. É interessante lembrar que no início do Departamento de Psicologia [da UnB], quando eu vim em 1975, havia uma pluralidade de pessoas e de enfoques, e isso foi muito bom, porque nem sempre isso acontece. É importante que as pessoas se relacionem, que sejam capazes de ver isso, de buscarem esses pontos de interseção, de interface, conservando a pluralidade mas desenvolvendo uma maneira de ver o homem integral, integrado à sociedade em seu momento. Eu acho que a gente pode ter várias vertentes, e inclusive isso vem ajudar muito na própria clínica, na Psicologia da Educação (...). É preciso saber dialogar, dentro da própria Psicologia. O diálogo é necessário. 
Diva - Parece que hoje já se pode ver mais sinais de que pode haver...

Thereza - Eu acho que tem que começar dentro da universidade, é evidente que na vida profissional também. Eu fiz uma trajetória paralela à univesidade, fui sempre uma pessoa engajada, me interessei não só pela vida acadêmica mas por participar de associações, ajudei a fundar associações, e depois o próprio Conselho de Psicologia. Fui presidente do Conselho Regional, sempre preocupada em encontrar uma maneira de estabelecer o nosso lugar ao sol. Trabalhando na universidade, na formação, mas também vendo o que se podia fazer para o profissional no campo. Por exemplo, hoje essas brigas estão se repetindo com o Ato Médico, exatamente a mesma coisa, que considera a Psicologia apenas como uma especialidade da área médica. É preciso se trabalhar em equipe, mas cada um tem que saber e [ter respeitada] a sua contribuição, para que a gente possa se articular (...) temos que nos articular com os médicos, os assistentes sociais, os juízes etc. Mas a Psicologia não é uma área subsidiária, é uma área de conhecimento que tem o seu valor per se, o estudo do comportamento, do desenvolvimento humano não se confunde com as outras áreas, embora ela tenha interfaces com elas. É interessante ver como o crescimento da Psicologia no Brasil é exponencial, é impressionante!

Diva - Thereza, você acha que a Psicologia pode contribuir para uma sociedade mais ética?

Thereza - Deve, deve contribuir. Acho que nós todos. A Psicologia pode, como o educador também pode, e nós, que trabalhamos com o desenvolvimento humano, nós somos um parceiro importante, que tem que se formar para ajudar o desenvolvimento da ética. Por exemplo, a violência. Como nós podemos lidar com a questão da violência? (...) A violência a gente vê hoje na televisão, a gente está vendo agora, dentro da nossa casa. Eu acho uma tarefa incrível, difícil, mas nós temos que lutar para melhorá-la. É necessária uma mudança de atitude: prevenção, com certeza. E a religião, qual o papel dela? O que que foi feito da religião? Antes se dizia que esse era o papel da religião, que está acabando. A religião se perdeu, ficou exacerbada, fanática, e os valores ficaram perdidos, sem mais valores. A Psicologia é pequena para dar conta disso, a coisa é muito mais ampla, mas agora temos nossa parte, nós temos que estudar isso, como é que se desenvolvem os valores, junto com a Sociologia e a Antropologia. Que valores são esses que estão aí em nossa sociedade, é o individualismo, o consumismo? No momento em que nós não temos hoje, por exemplo, na política, a questão do socialismo, do capitalismo, toda essa questão política, que valores são esses? Então a função da Psicologia é, primeiro, identificar isso. Como esses valores, que a Angela [Angela Branco] está estudando e você também, como é que se desenvolvem esses valores? Que valores são esses? E quando, como é que a gente muda isso? O que é o verdadeiro humanismo? Quem é que vai descobrir isso? São os idealistas? No campo social e politico, que capitalismo é esse, que tipo de liberalismo é esse, e como é que isso está formando o nosso pessoal, como nós podemos sair disso, não é? Eu acho que a Psicologia tem, sim, mas não sozinha, e a Psicologia do Desenvolvimento tem que procurar discutir com a educação e ver se a gente consegue, inclusive, mudar os valores do nosso representante, ele tem um ideário e quando chega no governo, muda tudo. O poder muda e coloca em cheque os verdadeiros valores das pessoas!

Diva - Você gostaria de dizer algumas palavras para os estudantes brasileiros de Psicologia?

Thereza - Algumas coisas, eu creio, eu já falei, mas poderia acrescentar que o psicólogo tem uma missão especial, é evidente que dependendo da área em que vai trabalhar ele irá ter maior ou menor função direta na sociedade. Mas mesmo quem trabalha na área básica, como na área da Biologia, na área da Física, essas ciências básicas têm como função formar os alunos. Mas a maior parte das especialidades da Psicologia implica em um trabalho com pessoas. A Psicologia Animal, também, tem sua importância, nós vivemos em um mundo integrado (...). Hoje a visão ecológica, ambientalista, é muito importante para a compreensão desta integração e para o alcance do equilíbio ambiental. Mas o que gostaria de dizer para os estudantes é sobre a importância da competência. Não pode só ser mediano, é necessário desenvolver a competência, estudar, e procurar se integrar na sua comunidade. E ver qual a sua verdadeira vocação, decidir em que área vai trabalhar, suas aptidões. Eu acho também que a Psicologia tem que saber utilizar a mídia. Eu acho que está faltando Psicologia nesse meio. Por exemplo, orientar os estudantes sobre as áreas novas, como a área da política, a Psicologia Política, por exemplo, como é que se resolvem conflitos. Os negociadores, quanto de conhecimento da Psicologia será que ele precisa, para ser mensageiro da paz? Então eu acho que a gente tem que entrar nessas areas também, quer dizer, a Psicologia tem áreas novas que precisam ser exploradas e os estudantes tem que sair preparados. Eu acho que a universidade tem que dar disciplinas diferentes que atendam essas necessidades. Por exemplo, a problemática da Paz, o que é a negociação? Por que que nós não estudamos isso? Temos que atuar também na área do trabalho, das relações humanas, na área da saúde também, como é que essas relações humanas acontecem, se você tem uma equipe, como é que essa equipe funciona? Eu acho que isso é muito importante e é também contribuição da Psicologia Social. Mas ela não pode ser uma Psicologia partidária.

\section{Diva - O que você quer dizer com partidária?}

Thereza - É quando você reduz a ciência à uma atividade partidária, aí você perde a visão do todo, dos seus objetivos, seja esta visão qual for, seja religiosa, de partido político, qualquer um deles. Não é que o psicólogo não deva ser politico, mas a Psicologia dele, se ele quiser compreender o mundo e ajudar com seu trabalho, essa Psicologia não pode ser partidária. Esse é o grande problema da mistura de uma "religião" com a Psicologia. Seja ela qual for... Quando você se torna um arauto partidário, você já não está fazendo uma Psicologia científica.

\section{Considerações Finais}

Ao finalizar este texto, acreditamos ser muito importante agradecer à Thereza Pontual de Lemos Mettel pela entrevista 
concedida, e por seus conhecimentos e competências que, de forma tão dedicada e generosa, vem compartilhando com todos nós. Agradecer pela seriedade, capacidade de planejamento e realização concreta de objetivos, por sua dedicação à vida acadêmica e à profissão de psicolólogo. Mas em especial, agradecemos a ela por sua sensibilidade e sabedoria, que se estende do conhecimento amplo e profundo em nível teórico, à pratica de uma convivência alegre, inspiradora e otimista, que sempre primou pela ética mais responsável e transparente, pela dignidade, pela tolerância, e pela aceitação e estímulo à diversidade pessoal e intelectual, ambas tão necessárias à construção do saber científico, e à formação integral dos seres humanos. 